Association for Information Systems AIS Electronic Library (AISeL)

December 2004

\title{
Information flows in a New Zealand Sheep Meat Supply Chain
}

Andreas Schroeder

Victoria University of Wellington

Beverley Hope

Victoria University of Wellington

Follow this and additional works at: http://aisel.aisnet.org/acis2004

\section{Recommended Citation}

Schroeder, Andreas and Hope, Beverley, "Information flows in a New Zealand Sheep Meat Supply Chain" (2004). ACIS 2004

Proceedings. 63.

http://aisel.aisnet.org/acis2004/63

This material is brought to you by the Australasian (ACIS) at AIS Electronic Library (AISeL). It has been accepted for inclusion in ACIS 2004

Proceedings by an authorized administrator of AIS Electronic Library (AISeL). For more information, please contact elibrary@aisnet.org. 


\title{
Information flows in a New Zealand Sheep Meat Supply Chain
}

\author{
Andreas Schroeder \\ Beverley G. Hope \\ Victoria University of Wellington, New Zealand \\ andreas.schroeder@vuw.ac.nz \\ beverley.hope@vuw.ac.nz
}

\begin{abstract}
Most supply-chain research focuses on manufactured goods supply chains. This paper aims to fill a gap in the literature by exploring the downstream information flows in a New Zealand sheep-meat supply chain. It identifies stakeholders and the nature and efficiency of their information exchanges. Results show that important information is generated in several tiers along the supply chain but this information is not always shared and opportunities for increased supply chain competitiveness are lost. The lack of information sharing is explained by the unwillingness of partners to commit to tight contractual agreements, the lack of adequate technological infrastructure, and the absence of regulations mandating certain information.
\end{abstract}

\section{Keywords:}

supply chain management, SCM, information flows, primary sector, agriculture

\section{INTRODUCTION}

For more than a hundred years sheep meat has been produced in New Zealand for local consumption and export. Although New Zealand's economy today is less dependent on its primary industries than in the past, sheep meat is still a major export earner and its production and processing provides employment opportunities for many New Zealander's.

A carefully coordinated supply chain would provide New Zealand's sheep meat industry with new capabilities in efficiency of production and processing, as well as an increased responsiveness to consumer preferences. In addition, and perhaps most importantly, it would prepare the industry to meet possible future international requirements for traceability. A key element in improved supply chain operation is the integration of information flows, which in the agricultural context not only facilitates operations but can also add value to products and provide confidence to the consumer. A sophisticated supply chain with carefully coordinated information flows will lead the New Zealand's sheep meat industry into the 21st century and better prepare it for future competition in the international market.

The research reported in this paper investigates the current state of the sheep meat supply chain in New Zealand, focussing particularly on downstream information flows. We interviewed major stakeholders in the supply chain to determine their information needs and the information they provide to their downstream partners. In the rest of this paper we report the various information flows and information media used, identify redundancies and deficiencies, and make recommendations for improvements.

\section{INFORMATION FLOWS IN THE SUPPLY CHAIN}

Modern competitive environments create pressure on organisations to form collaborative relationships along the supply chain. Supply chain management governs these collaborations by integrating "key business processes from end users through to original suppliers that provide products, services, and information that add value for customers and other stakeholders" (Lambert \& Cooper, 2000 p.66). Information flows are critical to successful supply chain relationships and their improvement is a major incentive in establishing supply chain integration (Buhr, 2000). Information sharing creates close collaboration between the supply chain members (Mariotti, 1999), has positive impacts on customer satisfaction (Singh, 1996), and can lead to the creation of new products and services, new marketing approaches, and advanced operations (Hoek, 1998).

Supply chain information flows can be divided into upstream flows, from retailers toward producers, and downstream flows, from producers toward retailers. The upstream flow may comprise information ranging from order details to the sharing of customer requirements and strategic decisions (Sahin \& Robinson, 2002). Objectives include desire for cost-savings through inventory reduction, decreased order magnification, and reduced time delays in fulfilment (Lee et al., 1996, cited in Zhao, Xie, \& Zhang, 2002). The downstream flow 
may comprise product details, product origin and destination, detailed shipment and invoicing information (Sahin \& Robinson, 2002). Even though most studies concentrate on the upstream flow both upstream and downstream information flows are crucial for both simple and complex supply chains (Singh, 1996)

Due to the importance of information, information technology is often considered the backbone of a supply chain (Sanders, 2002). This frequently includes sophisticated software and hardware components providing flexibility of operation to handle last-minute orders, order changes, mechanical failures, picking and packing errors, coordination failures, and data corrections (Hull, 2002). However, technology only enables information exchange; humans are the source of information and the drivers of technology. Consequently, people still play the pivotal role in supply chain environments and the relationship between buyers and suppliers remains a vital element of a successful supply chain (see, for example, Kannan, 2002; Mariotti, 1999).

\section{Supply chain management in the primary industry}

Supply chain management first became an issue in the manufacturing industry and the processes and components of modern supply chain management reflect this origin. In considering supply chain management in the primary industry, we need to take into account differences in the business environment, product characteristics, and the importance of downstream information flows.

The business environment in the primary industry is characterised by horizontal alliances such as co-operatives, rather than the vertical partnerships most often found in the manufacturing industry (Hobbs \& Young, 2000). In addition, primary product sale and distribution is often carried out through intermittent auctions or less involving regulated markets. The horizontal alliances and product distribution mechanisms reduce the direct interaction between producer and buyer and inhibit development of a closer relationship (O'Keeffe, 1998). An additional factor inhibiting supply chain integration in the primary industry is the lack of information technology experience and confidence of some members (Salin, 2000). This inexperience, coupled with perceptions of high costs and risks of information technology use, forms a considerable obstacle to the development of a sophisticated supply chain (Bailey, Norina, \& Cassavant, 2002).

Product characteristics also provide a point of differentiation between primary and manufacturing industries. In manufacturing, production can be scheduled with relative precision so that output can be known in advance and adjusted to meet changing demand. By contrast, output of agricultural products cannot be precisely known in advance due to vagaries of weather, disease, and rate of natural increase in stock. Furthermore, the time necessary to grow crops and animals for consumption means it is impossible to adjust supply at short notice. Product quality is also a critical concern, necessitating high standards in handling, storage, and transportation systems (Jongen \& Meulenberg, 1998). Consumers can be very sensitive to certain attributes of agricultural products and marketing needs to cater local preferences in terms of product presentation, product variety, and packaging. This is particularly important where product is destined for international distribution (Jongen \& Meulenberg). These product characteristics create unique challenges for the coordination of an agricultural supply chain.

The business environment and product characteristics in the agricultural industry create specific requirements on supply chain information flows. In many non-agricultural supply chains the focus is primarily on upstream information flows signalling demand fluctuations. By contrast, in the agricultural industry, equal or greater emphasis is placed on downstream information flows concerned with ensuring hygiene, safety, and quality requirements are met. Having appropriate information systems in place to signal production conditions (such as organically raised) and product handling (including halal meat preparation), facilitates the development of trust in the product by verifying that product meet the criteria and preferences of the consumer (Dorp, 2003; Jongen \& Meulenberg, 1998). Downstream information flows assist in providing traceability of product, which contributes to food-safety and communicates diligent operations to the consumer (Dorp, 2003; Wilson \& Clarke, 1998). The meat industry in particular has a high need for traceability and appropriate technologies to meet health requirements (Mousavi, Sarhadi, Lenk, \& Fawcett, 2002). Thus, the information flows in an agricultural supply chain have specific points of difference from those in manufacturing supply chains. In particular, there is an emphasis of downstream information flows and traceability instead of only upstream demand information flows.

\section{Agricultural SCM in NZ}

New Zealand's geography, climate, and long history in agricultural exporting have made it one of the world's most efficient producers of quality agricultural products (Ministry of Agriculture and Forestry, 2002). It achieves this efficiency without employing formal supply chain management principles to the same extent as in other OECD-countries (Basnet, Corner, Wisner, \& Tan, 2003). The relative lack of supply chain management in New Zealand's industry in general may be attributed to its small and thinly spread population, its lack of any supply chain intensive manufacturing industry to provide an example, and the "relative lack of leverage of New Zealand 
firms to bring about change“ (Basnet et al., 2003). Yet meat industry products, including sheep meat, contribute strongly to the New Zealand economy by being the second largest export income earner (Statistics New Zealand, 2000). Sophisticated supply chain processes may improve its competitiveness through its ability to provide safe and reliable quality products and to add value to the products by ensuring standards are met, providing traceability, and generally demonstrating reliability (Penny, 2003).

At the time of writing, advanced information systems are in place only for the cattle-beef supply chain while the sheep meat industry seems to make less use of information technology. This suggests room for improvement. The first step is an assessment of the current situation. An understanding of the downstream information flows is a crucial component for the sheep meat supply chain, and it is this information flow which is addressed in this research.

\section{RESEARCH METHODS}

Being an exploratory study, the primary concerns in this research were the identification of stakeholders in the sheep meat supply chain, the information they sought and supplied, the media used for its distribution and storage, and, ultimately, to identify redundancies and inefficiencies in information flows. We aimed to not only understand what was happening, but also why it was happening, that is, to understand the motivators and reasons for what was happening. Hence, a case research methodology in line with recommendations of Benbasat (1987) seemed appropriate. Data collection and analysis followed procedures introduced by Creswell (2003).

Informants included representatives of organisations directly involved in the supply chain and others with an oversight function. Informants directly involved in the supply chain included a sheep farmer, stock-agent, meat processor, a meat-wholesaler, supermarket butcher, and an independent butcher. Those with an oversight function included the Director of the Meat Industry Association, and a field representative of a Food \& Safety Authority. Our interview with the Director of the Meat Industry Association provided us with background knowledge with which we could prepare for our further interviews. In addition, this informant was able to provide a high-level view of what was happening in the industry and what the future might hold.

Semi-structured interviews were designed to gather specific information whilst also allowing for unexpected data to emerge. Most interviews were carried out in July 2003 with three more completed in January 2004. Interviews took between 30 and 60 minutes, and each was transcribed in full upon completion. Subsequently the interviews were analyzed following the generic steps suggested by Creswell (2003) for analysing and interpretation of qualitative data. These 'generic steps of data analysis' proved to be a valuable guideline for the purpose of this research and significantly contributed to the outcome of the investigation.

\section{RESULTS}

In this section we first provide a brief summary of each of the stakeholders in the sheep meat supply chain followed by an analysis of the information flows.

\section{Stakeholders}

The present supply chain investigation focuses on the domestic product and information flows of a single meat processing plant and its suppliers, customers, Food \& Safety inspectors, and associated livestock agents. The director of the national Meat Industry Association was also interviewed, to provide a broader, high level perspective. The relationship among these stakeholders is shown in Figure 1. The primary product flow is simple: farmer to processor (via a transporter and sometimes via a spot market), from processor to butcher (via refrigerated wagons). In this, as in many other supply chains, the retailer is considered the 'customer' - the end of the chain. Relative to product flows, information flows are more complex and involve other players. These other players include livestock agents, food and safety officials, transporters, and auditors, as well as overseeing bodies such as the Meat Industry Association. We briefly describe each stakeholder before turning our attention to the information flows. 


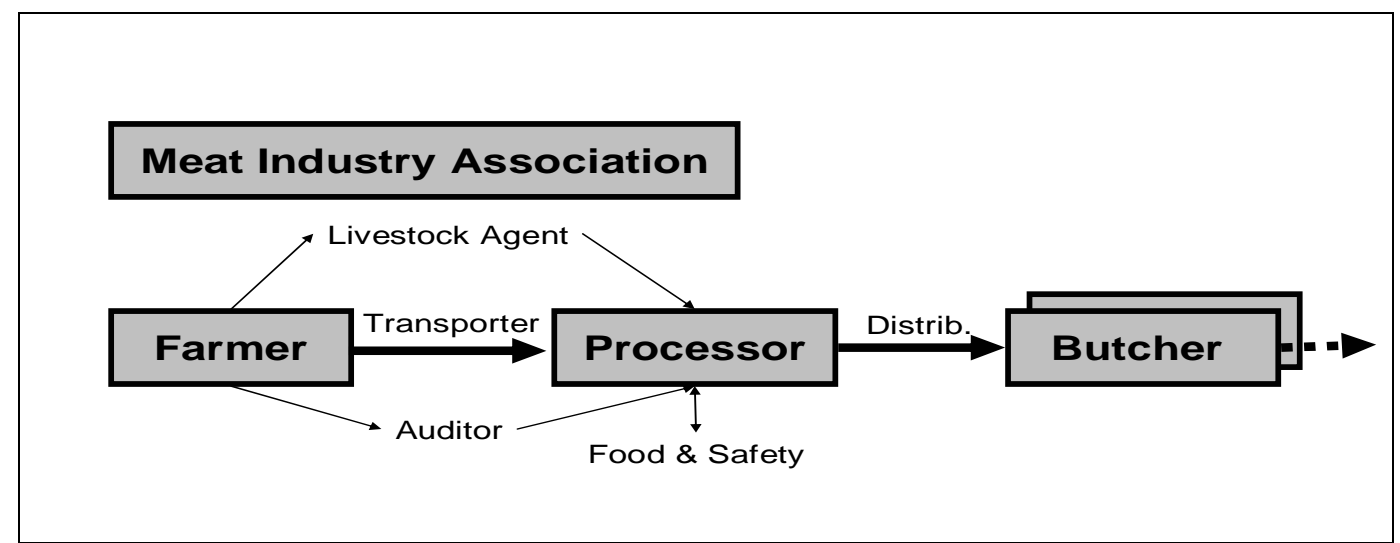

Figure 1: Stakeholders in the sheep meat supply chain

\section{Farmer}

The medium-sized commercial sheep farmer interviewed for this study raises sheep both for meat production and for sale as breeders. On the meat production side, he was not bound into supply contracts to any particular meat processor but sold to whoever paid the most at any particular time. In seeking to provide optimal growing conditions the farmer shifted sheep between paddocks, monitored their health status, administered vaccinations and, where needed, treated them with remedies. Regulations require the farmer to keep a record of these activities in the form of remedy use records. This ensures transparency in the growing phase of the sheep and is regularly audited. Each meat-processor provides its own specific booklets for this recording, and only by keeping these upto-date will the farmer be able to sell sheep to a particular processing company. The farmer was displeased with this requirement, and interpreted it as a strategy of meat processors to increase farmer dependency. The farmer informant tagged individual sheep and kept individual record for each sheep. This, he acknowledged, was not normal process but related to the sheep breeding side of his business.

The farmer did not consider meat-supply contracts to be beneficial to his business model since it "would cut [him] out of a lot of flexibility." Rather, the sheep are sold directly to meat processor or through a live stock-agent when necessary. The role of the stock agent was considered valuable, as he had a better overview of the market. When sheep are ready for sale, a transporter takes the sheep, accompanied by an animal status declaration completed by the farmer, to the processor. Approximately ten days later the farmer receives a 'killing-sheet' in which the meat processor states the 'yield' obtained from each sheep and any premiums granted. Having to wait ten days for the killing sheet was not considered satisfactory by the farmer, since the results could not be considered for subsequent selling decisions. The farmer communicated with other supply chain members mostly via telephone, fax and post. Computer-mediated communication was not used because transmission rates in his rural location were very low.

\section{Stock Agent}

The Stock Agent played a pivotal role in the livestock market, acting as an information intermediary between buyers and sellers who were geographically, industrially and organizationally dispersed. From his perspective as a 'market insider' the Stock Agent observed that the downstream information flow received more attention in recent years. For example, while formerly the animal status declaration would often be filled out unsatisfactorily, "because [farmers] don't inherently like filling out forms," today no trading of stock can be effected without correctly completed forms. Hence, the reliability of the information provided has increased. The Stock Agent opined that traceability and individual tagging of the sheep would soon become a serious issue.

\section{Meat Processor}

The meat-processor considered for this study was a single-plant operator located in the lower North Island dedicated to the procurement, slaughtering and exporting of sheep and beef meat, and capable of halal processes. Sheep were procured from farmers or on spot markets. Fixed term supply contracts were not considered a viable option due to the many unpredictable factors. In lieu of contracts, the company focused on the establishment of trust, reliability, and good relationships with farmers through loyalty schemes. Although no supply contracts were used to specify desired quantities and quality, price sent a signal to farmers, as the Meat Processor commented, "[which is], to be honest, is a very blunt signal." By contrast, on the demand side, the processor entered into very prescriptive contracts with overseas customers. These contracts prescribed the date of delivery as well as quantity and product specifications. 
The most important information flows to and from the meat processor are those related to health and safety concerns. Upon delivery of a load of procured sheep the transporter hands over the animal status declaration previously completed by the farmer. The Food \& Safety Authority inspects sheep in the holding pens and a clearance form is stapled to the pen gate. A second food safety inspection follows post-mortem and the Food \& Safety Authority representative declares the product suitable for human consumption. Following slaughter, carcasses may be packed whole, disassembled into 10-15 pieces and put into cartons, or minced. Most output is subsequently frozen and shipped overseas, leaving only a small portion in the New Zealand domestic market.

\section{Food \& Safety Authority}

The Food \& Safety Authority official interviewed was one of a small team of officers located within the premises of the meat processing plant. The role of the team was to monitor the activities in the meat-processing plant to ensure that activities and processes complied with regulations. The responsibility starts with the ante-mortem inspection of the animals in holding pens. This includes checking information on the animal status declaration and compliance with any withholding periods related to vaccinations or treatments administered to the animal. In reaching their decision to 'pass' the animals ante-mortem, reliance is placed on the accuracy of the information supplied by the farmer on the animal status declaration. Consequently, trust plays a major role in the approval process. Farmers found to provide false information are put on a suspect list, which leads to separate verification process in selling sheep. Once a pen of animals is passed, a pen-card is stamped with a "passed veterinary inspection“.

Prior to slaughter the Food \& Safety Authority is provided with a killing-sheet declaring which animals are soon to be processed. Post-mortem inspection commences after the slaughter and dressing process are complete. Carcasses are inspected by a separate Food \& Safety team and, when passed, declared as fit for human consumption. In the case of export, Food \& Safety representatives issue an electronic certificate stating that the product meets legal and contractual requirements. Meat destined for the domestic market does not get further certification beyond the 'fit for human consumption' declaration. All food and safety documents including pencards, animal status declarations, and kill-sheets are stored in paper form for specified retention periods by either the Food \& Safety Authority or the Meat Processor.

\section{Meat Industry Association}

The Meat Industry Association (MIA) represents the national and international interests of New Zealand's meat processors and provides a strategic orientation for the industry as a whole. Their perception of the industry indicates a shift from the original "freezing-business" to the "food-business" with the introduction of automated processes employing robotic and information technology. They also envision increased collaboration between farmers and processors in terms of shared market information and drafting of long-term contracts which might establish 'farming on demand' where " [the meat processor] can be confident that the farmer will send ... raw material ... on the right day and of the right weight." Information and communication technology is considered a major enabler of these shifts in the industry and dramatic change, particularly with respect to market responsiveness, is expected within the next 10 years.

\section{Retailer and Butchery}

Interviews were conducted with a meat wholesaler/retailer, a supermarket butcher, and a small independent butcher. Although the three stakeholders operated on different scales they maintained similar processes in ordering, handling and distributing meat to consumers. All three ordered product by telephone. This was considered "easy" and a means by which they could maintain the relationship with the processor and receive further information about the product. The requirement criteria of each outlet were known to the meat processor, who could allocate product to meet these criteria thereby reducing rejection rates. Identification tags attached to carcasses within the processing plant were not considered by any of the butchers. Rather, they relied on personal backdoor inspection of the carcass - the small butcher was not even able to interpret the information on the identification tag.

Butchers process carcasses to meet the requirements of consumers, adding labels with limited additional information beyond packed on and use by dates. Rarely do consumers request information exceeding that provided on the labels. Most queries received relate to preparation of the meet or suitability for particular dishes. The provision of more detailed information such as breed of cattle, region or origin, or feed regimes (organic, grain fed) are not considered important by the average shopper and are not often used to add value to the product.

All three butchers stated that they would not be able to reliably trace a particular piece of meat back to the carcass from which it was taken. So, although carcasses are uniquely identified via the meat processor's tag, traceability is lost as the butcher process meat for sale from several carcasses at the same time. The most the butcher could 
state is that it came from one of a set of carcasses. While traceability is not a current concern, it is likely to become so in the future. Stakeholders seemed to consider that this "will be dealt with when we come to it".

\section{Analysis of information flows}

The downstream information flow in the supply chain included structured information flows carrying discrete recorded information on form-sheets and unstructured verbal information flows. The structured downstream information included the animal status declaration, animal remedy use record, carcass tags, quality checklist, and product labels (Table 1).

Table 1: Overview of the structured information flows

\begin{tabular}{|c|c|c|c|c|c|}
\hline Artefact & Content & Purpose & Originator & Recipient & Media \\
\hline $\begin{array}{l}\text { Animal } \\
\text { status } \\
\text { declaration }\end{array}$ & $\begin{array}{l}\text { History of feeding, } \\
\text { vaccinations, } \\
\text { diseases, treatments }\end{array}$ & $\begin{array}{l}\text { Declare the } \\
\text { status of the } \\
\text { sheep }\end{array}$ & Farmer & $\begin{array}{l}\text { Food \& Safety } \\
\text { Authority } \\
\text { (via meat } \\
\text { processor) }\end{array}$ & $\begin{array}{l}\text { Paper form } \\
\text { with carbon } \\
\text { copy }\end{array}$ \\
\hline $\begin{array}{l}\text { Animal } \\
\text { remedy } \\
\text { use } \\
\text { record }\end{array}$ & $\begin{array}{l}\text { Date, tally, stock } \\
\text { class, paddock or } \\
\text { mob I.D., } \\
\text { treatment, product } \\
\text { name, withholding } \\
\text { period }\end{array}$ & $\begin{array}{l}\text { Keep record of } \\
\text { the different } \\
\text { treatments the } \\
\text { sheep where } \\
\text { provided with }\end{array}$ & Farmer & $\begin{array}{l}\text { Processor } \\
\text { (via auditor) }\end{array}$ & Booklet \\
\hline $\begin{array}{l}\text { Carcass } \\
\text { tag }\end{array}$ & $\begin{array}{l}\text { Lot-number, } \\
\text { production date and } \\
\text { time, sex, quality } \\
\text { grading, body-fat, } \\
\text { weight, bar-code }\end{array}$ & $\begin{array}{l}\text { Identify the } \\
\text { carcass }\end{array}$ & $\begin{array}{l}\text { Meat } \\
\text { processor }\end{array}$ & $\begin{array}{l}\text { Butcher } \\
\text { (but it is not } \\
\text { considered) }\end{array}$ & Paper \\
\hline $\begin{array}{l}\text { Quality } \\
\text { checklist }\end{array}$ & $\begin{array}{l}\text { Date, delivery } \\
\text { number, } \\
\text { temperature, } \\
\text { observations }\end{array}$ & $\begin{array}{l}\text { Recording of } \\
\text { deficiencies in } \\
\text { the incoming } \\
\text { temperature }\end{array}$ & $\begin{array}{l}\text { Supermarket } \\
\text { butcher }\end{array}$ & $\begin{array}{l}\text { Own use } \\
\text { (supermarket) }\end{array}$ & Paper form \\
\hline $\begin{array}{l}\text { Product } \\
\text { label }\end{array}$ & $\begin{array}{l}\text { Packed by date, } \\
\text { product weight, } \\
\text { price }\end{array}$ & $\begin{array}{l}\text { Informing } \\
\text { consumer of } \\
\text { product } \\
\text { freshness }\end{array}$ & $\begin{array}{l}\text { Supermarket } \\
\text { butcher }\end{array}$ & Consumer & Paper \\
\hline
\end{tabular}

\section{Animal status declaration}

The animal status declaration is a legal, paper-based form detailing the animal's history, special treatments feeding supplements, vaccinations and remedies. This is prepared by the farmer with respect to the traded sheep and subsequently accompanies the sheep to the meat processor where it is examined and retained by the Food \& Safety Authority.

Animal remedy use records

The animal remedy use record is a collection of farm-specific data captured by the farmer and recorded in booklets. This record is required by the meat processors who provide the booklets to farmers. The record contains information on the translocation of individual sheep-mobs on different paddocks, medical treatments administered, and any 'withholding dates' during which the sheep must not be consumed due to medical treatment. Each meat processor with whom the farmer deals requires an independent and different record to meet their quality audit.

Other records

The killing sheet, which shows the slaughter schedule, is passed on paper from the meat processor to the Food \& Safety Authority. It outlines the intended slaughters to enable the Food \& Safety Authority to keep track of 
activities. A carcass tag is affixed to every carcass after slaughter. The tag contains an ID number and barcode that identifies the piece of meat and the processing plant. The product label affixed to the packaged meat by the butcher is another structured information flow that follows the product out of the chain to the consumer. The supermarket staff also kept a quality checklist on which the temperature and condition of the meat product was recorded.

Unstructured information flows also play an important role in the supply chain. These included information exchanges between the farmer and livestock agent, and between the farmer and the meat processor. These exchanges were made either by phone or in face-to-face encounters, and often included discussion of the quality and characteristics of the sheep to be traded. Another important unstructured information flow was the conversations between the butchers and the meat processors. Orders were completed over the telephone, and at the same time product information was communicated. The supermarket representative noted, "We get to know what is going on. [The sales representative] can tell ... straight away if the product is available or if it is not available - and other facts we need to know.” In general the unstructured information between the supply chain members was considered as important as structured information, since product is sold via "relationship marketing."

Table 2: Overview of the unstructured information flows

\begin{tabular}{|l|l|l|}
\hline Circumstance & Purpose of conversation & Communication media \\
\hline $\begin{array}{l}\text { Conversation between } \\
\text { farmer and livestock agent }\end{array}$ & $\begin{array}{l}\text { The farmer discusses with the } \\
\text { livestock agent the quality of the } \\
\text { sheep and the conditions under which } \\
\text { they should be sold. }\end{array}$ & Telephone or face-to-face \\
\hline $\begin{array}{l}\text { Conversation between } \\
\text { farmer and meat processor }\end{array}$ & $\begin{array}{l}\text { The farmer discusses with the meat } \\
\text { processor the quality of the sheep and } \\
\text { the conditions under which they could } \\
\text { be sold. }\end{array}$ & Telephone or face-to-face \\
\hline $\begin{array}{l}\text { Ordering process from } \\
\text { butcher to meat processor }\end{array}$ & $\begin{array}{l}\text { In the ordering process, the butcher } \\
\text { receives information about the } \\
\text { products available, confirms an order } \\
\text { and receives additional information } \\
\text { about the market-situation. }\end{array}$ & Telephone \\
\hline
\end{tabular}

\section{DISCUSSION}

The research suggests that information flows in the sheep meat supply chain in New Zealand do not follow the well coordinated and integrated information flows described in the manufacturing supply chains but rather forms isolated transfers of information between adjacent partners in the chain. .

The research identified six key participants in the sheep meat supply chain contributing to the downstream information flow: farmers, livestock agents, quality auditors, meat processors, the Food \& Safety Authority, and butchers. The 'end users' of the sheep meat are not considered an integral to the supply chain but are viewed as a separate entities referred to by supply chain members as 'consumers.' It is the retail butchers who are referred to as 'customers' by other supply chain members. This terminology used by the meat processor and farmer suggests that they do not see themselves as part of a distributed organizational structure with a common goal but rather as independent business entities seeking to satisfy the next entity down the chain. The meat processor dominates the supply chain. The processor is in a financially strong position with deep customer knowledge and, therefore, becomes the driver of change within the supply chain. The other members of the chain follow the processor's requirements and which in turn are being driven by overseas customers.

There was tension and lack of trust between farmer and processor, with the farmer voicing concerns over perceived abuse by the processor of their dominant position while the processor considered the farmers unreliable and opportunistic. In the case in question, both parties operated without a fixed supply contract. By contrast, the Director of the Meat Industry Association suggested there was strong success in contract farming. Given the small sample size in this study, it is not possible to generalize these findings and the need for further research is indicated.

The downstream information flow in the supply chain is largely restricted to exchanges between adjacent members, with no information accompanying the product all the way from the farm to the retail butcher. The 
Food \& Safety Authority accumulates quality related information and their quality assurance is relied upon by subsequent entities. Making more information available to the consumer is not considered to add value. Structured information flows within the domestic supply chain is effected via hand-written paper-based documents and the digitised information accumulated by the meat processor and the Food \& Safety Authority is not shared with other members. Unstructured information is conveyed between adjacent stakeholders within the chain through telephone and face-to-face encounters. These exchanges were considered very useful since they were both fast and easy, and they supported the exchange of information and feedback. More importantly, they were considered useful in helping to build relationships.

The research revealed several redundancies and inefficiencies in the information flow. For example, the farmer complained about the need to complete separate books of record for each meat processor, and also about the general use of paper-based information which demanded double handling and increased administrative effort for all parties. Some seemingly redundant information might not necessarily be redundant. For example, the distributor and butcher did not use the carcass tag affixed by the meat processor, yet it contained potentially valuable information. At the final stage only pack and use-by dates were communicated to consumers.

Product traceability was not considered an important issue, and the meat-processor could only approximately determine a carcass's origins by estimating production time and production run. Similarly butchers could not unambiguously trace any piece of meat back to the carcass from which it came.

The inefficiencies and redundancies in information flows provide room for improvement. Much of this could be achieved through the use of computer-based systems. For example, appropriate software could help the farmer to integrate his own livestock administration with the required quality documentation. This information could then be digitally transferred to the Food \& Safety Authority who could assess the record before arrival of sheep at the meat processor.

The traceability of the sheep meat in the supply chain could be advanced by assigning a personal identifier to all sheep throughout the entire supply chain. All members of the supply chain could be able to access and add to this information, hence transparency and traceability would be assured and redundant paper-based information handling could be minimized. Some of this information could be used by the supply chain to add value to the product, for example, identifying region of origin, breed, or organic feeding regimes.

\section{CONCLUSION}

"It is a fascinating business, we have seen more change in the last ten years than in the hundred years before... and information underpins everything." (MIA Director)

Despite this positive and convincing comment by the MIA representative, the study has shown that information flows are not yet used in an integrated way to support production and processing in New Zealand's sheep meat industry. Hence, despite recent improvements even more dramatic changes are necessary in the near future if New Zealand's sheep meat industry is to remain competitive in international markets.

The investigation of information flows between members of the sheep meat supply chain showed several insufficiencies in the generation and transfer of information which need to be addressed, for example, sheep are not consistently identified on farms and the farmer is required to keep redundant records in order to meet the requirements of different meat processors. Furthermore, available information within the supply chain was not used to add value to the product, and no processes to assure traceability were identified. The lack of end-to-end information flows and lack of trust indicate low levels of integration among supply chain partners.

In addition to pointing out the insufficiencies in the current supply chain situation, the study suggested possible areas for improvement in information flows. Most important in this regard is the suggestion that the integration of information flow could become a starting point for a re-conceptualising of the current supply chain situation. The development of a common information platform would not only facilitate the introduction of traceability but would also bring the different stakeholders of the supply chain closer together which may ultimately lead to the generation of new business models and value prepositions for the customer.

\section{Limitations and future research}

The present research followed a rigorous methodology, however, the relatively small number of participants and concentration on a single supply chain limit the generalisability of the findings. Future studies investigating the information flows of sheep meat supply chains should include more representatives at each tier in the sheep meat supply chain. This would provide data on a greater variety of business interactions and different perspectives. In particular, the internal information handling of the meat processor warrants further investigation since the meat processor is the dominating stakeholder in the supply chain and any initiatives for improvement would require 
their support. So, future studies should aim at an in-depth understanding of processes and perspectives of the meat processors and should include interviews with representatives at different organizational levels.

It would also be useful to investigate the information needs of the consumers. Knowledge about the information requirements of consumers would provide the industry with incentives to use information to add value to the product. In this context the information requirements of the overseas customers should also be addressed in future research since it can be expected that their needs would drive any innovation in information flows.

Even though New Zealand's sheep meat industry went through many changes in its recent history, there are more to come. In order to remain competitive in the 21st century, the agricultural industry has to overcome old structures, make use of new technologies, and be creative in their application. This research has made it clear that once the members of the supply chain improve information exchanges their collaboration will also improve. This seems to be universally applicable - regardless of whether the product is sheep meat or a manufactured good.

\section{REFERENCES}

Bailey, W. C., Norina, L., \& Cassavant, K. (2002). The use of supply chain management to increase exports of agricultural products. Retrieved March, 2003, from http://www.ams.usda.gov/tmd/SCM/SCM_Ag.pdf

Basnet, C., Corner, J., Wisner, J., \& Tan, K.-C. (2003). Benchmarking supply chain management practice in New Zealand. Supply Chain Management: An International Journal, 8(1), 57-64.

Benbasat, I., Goldstein, D., \& Mead, M. (1987). The Case Research Strategy in Studies of Information Systems. MIS Quarterly, 11(3), 369-386.

Buhr, B. (2000). Information technology and changing supply chain behaviour: Discussion. American Journal of Agricultural Economics, 82(5), 1130-1132.

Creswell, J. W. (2003). Research Design: Qualitative, Quantitative, and Mixed Methods Approaches. Thousand Oaks, California: Sage Publications.

Dorp, K. J. (2003). Beef labelling: The emergence of transparency. Supply Chain Management: An International Journal, 8(1), 32-40.

Hobbs, J. E., \& Young, L. M. (2000). Closer vertical co-ordination in agri-food supply chains: A conceptual framework and some preliminary evidence. Supply Chain Management: An International Journal, 5(3), 131-142.

Hoek, R. I. v. (1998). Logistics and virtual integration: Postponement, outsourcing and the flow of information. International Journal of Physical Distribution \& Logistics Management, 28(7), 508-523.

Hull, B. (2002). A structure for supply-chain information flows and its application to the Alaskan crude oil supply chain. Logistics Information Management, 15(1), 8-23.

Jongen, W. M. F., \& Meulenberg, M. T. G. (1998). Innovation of Food Production Systems. Wageningen: Wageningen Pers.

Kannan, V. R. (2002). Supplier selection and assessment: Their impact on business performance. The Journal of Supply Chain Management, 38(4), 11-21.

Lambert, D. M., \& Cooper, M. C. (2000). Issues in supply chain management. Industrial Marketing Management, 29, 65-83.

Mariotti, J. L. (1999). The trust factor in supply chain management. Supply Chain Management Review, 3(1), 70-77.

Ministry of Agriculture and Forestry. (2002). Situation and Outlook for New Zealand Agriculture and Forestry. Retrieved 12 July, 2004, from http://202.78.129.207/mafnet/rural-nz/statistics-andforecasts/sonzaf/2002/sonzaf-2002.pdf

Mousavi, A., Sarhadi, M., Lenk, A., \& Fawcett, S. (2002). Tracking and traceability in the meat processing industry: a solution. British Food Journal, 104(1), 7-19.

O'Keeffe, M. (1998). Establishing supply chain partnerships: Lessons from Australian agribusiness. Supply Chain Management: An International Journal, 3(1), 5-9.

Penny, G. M. (2003). Supply chain (re)alignment in New Zealand's sheep meat and dairy industries: Knowledge, networks and learning at the farmer-processor site. New Zealand: University of Auckland. 
Sahin, F., \& Robinson, E. P. (2002). Flow coordination and information sharing in supply chains: Review, implications, and directions for future research. Decision Sciences, 33(4), 505-536.

Salin, V. (2000). Information technology and cattle beef supply chains. American Journal of Agricultural Economics, 82(5), 1105-1111.

Sanders, N. R. (2002). IT applications in supply chain organizations: A link between competitive priorities an organizational benefits. Journal of Business Logistics, 23(1), 65-83.

Singh, J. (1996). The importance of information flow within the supply chain. Logistics Information Management, 9(4), 28-30.

Statistics New Zealand. (2000). New Zealand Official Yearbook. Retrieved 2004, 12 July, from http://www.stats.govt.nz/domino/external/Web/nzstories.nsf/092edeb76ed5aa6bcc256afe0081d84e/89b fc36cef20ede5cc256b1f0000b8dc?OpenDocument

Wilson, T. P., \& Clarke, W. R. (1998). Food safety and traceability in the agricultural supply chain: Using the internet to deliver traceability. Supply Chain Management, 3(3), 127-133.

Zhao, X., Xie, J., \& Zhang, W. J. (2002). The impact of information sharing and co-ordination on supply chain performance. Supply Chain Management: An International Journal, 7(1), 24-40.

\section{COPYRIGHT}

Andreas Schroeder \& Beverley Hope (C) 2004 assign to ACIS and educational and non-profit institutions a nonexclusive licence to use this document for personal use and in courses of instruction provided that the article is used in full and this copyright statement is reproduced. The authors also grant a non-exclusive licence to ACIS to publish this document in full in the Conference Papers and Proceedings. Those documents may be published on the World Wide Web, CD-ROM, in printed form, and on mirror sites on the World Wide Web. Any other usage is prohibited without the express permission of the authors. 